\title{
HUBUNGAN MEROKOK DENGAN KAPASITAS VITAL PARU PADA BURUH PELABUHAN PULAU BAAI BENGKULU TAHUN 2009
}

\author{
Septiyanti, Gusnilawati, Susiwati \\ Jurusan Keperawatan Poltekkes Kemenkes Bengkulu Jl. Indragiri No.3 Bengkulu \\ Jurusan Keperawatan Poltekkes Kemenkes Bengkulu JI. Indragiri No.3 Bengkulu \\ Jurusan Analis Kesehatan Poltekkes Kemenkes Bengkulu Jl. Indragiri No.3 Bengkulu
}

\begin{abstract}
The ability of the lungs to expand, which mean's a person's ability to use respiratory muscles to expand the chest depend on smoking activity and daily activity. The purpose of this research is to know the relationship between smoking with vital lungs capacity of the worker in Baai Island Harbour at 2009. This research using cross sectional design. The independent variable; smoking habits, nutritional status, age and history lungs disease and vital lungs capacity as dependent variable. Sample as 50 people. Data were analyzd by univariat frequency distributions, with bivariate chi-square test. The result of this research there's a relationship between smoking with vital lungs capacity of the worker in Baai Island Harbour 2009, after controlling disease history ( $\rho$ value 0,11 , PR 9,20,95\% CI 1,67-50,65. More efforts should be intensified promotion and prevention to stop smoking in public, especially in the productive age group by explaining the effects that can be caused by smoking, both for the smoker himself and for others around them.
\end{abstract}

\begin{abstract}
Abstrak : Kemampuan paru-paru dalam mengembang yang berarti kemampuan sesorang dalam dalam menggunakan otot-otot pernafasan untuk mengembangkan rongga dada tergantung dari kebiasaan merokok dan aktifitas seseorang. Tujuan penelitian adalah diketahuinya hubungan merokok dengan kapasitas vital paru pada buruh pelabuhan Pulau Baai Bengkulu tahun 2009. Penelitian menggunakan desain cross sectional. Variabel independen: kebiasaan merokok, status gizi, usia dan riwayat penyakit paru; dan variabel dependen: kapasitas vital paru. Sampel sebanyak 50 orang. Data dianalisis secara: univariat dengan distribusi frekuensi, bivariat dengan uji chisquare, multivariat dengan regresi logistik ganda model faktor resiko. Hasil penelitian antara lain: ada hubungan merokok dengan kapasitas vital paru buruh pelabuhan pulau baai Bengkulu tahun 2009 , setelah dikontrol riwayat penyakit paru sebelumnya (nilai $\mathrm{p}=0,11, \mathrm{PR}=9,20,95 \% \mathrm{CI}=$ 1,67-50,65). Hendaknya lebih menggiatkan usaha promotif dan preventif berhenti merokok pada masyarakat, terutama pada kelompok usia produktif dengan menjelaskan dampak-dampak yang bisa ditimbulkan oleh rokok, baik bagi si perokok sendiri maupun bagi orang lain di sekitarnya.
\end{abstract}

Kata kunci: merokok, kapasitas vital paru.

Tembakau adalah salah satu penyebab yang paling penting untuk kecacatan, penderitaan dan kematian prematur. Asap tembakau mengandung ribuan bahan kimia, banyak diantaranya sudah dikenal sebagai racun. Beberapa bahan kimia ini merusak pembuluh darah dan menyebabkan kanker serta dapat merusak semua bagian tubuh. Lebih dari 4000 bahan kimia telah diidentifikasi dalam asap tembakau. Banyak diantaranya mengandung racun dan bersifat radioaktif (Crofton, 2009).

Banyak masyarakat yang sudah banyak tahu bahwa menghisap rokok adalah kebiasaan yang tidak sehat, karena dalam sap rokok banyak zat yang mengandung zat yang bersifat racun, antara lain tar, kar- bon monoksida (CO), nikotin, tetapi sampai sekarang masyarakat Indonesia masih banyak yang merokok, bahkan orang merokok bebas dilakukan di mana saja baik di kantor, kendaraan umum, di jalanan dan sebagainya (Mutadin, Z, 2002)

WHO juga memperkirakan pada tahun 2020 penyakit yang berkaitan dengan tembakau/rokok akan menjadi masalah kesehatan utama terbesar dan menyebabkan 8,4 juta kematian setiap tahun. Diperkirakan separuh kematian tersebut akan terjadi di Asia karena tingginya penggunaan tembakau di (WHO, 2006). WHO memperkirakan bahwa 59\% atau 140.687. 241 jiwa pria berusia di atas 10 tahun di Indonesia telah menjadi perokok harian, 
konsumsi rokok di Indonesia setiap tahun mencapai 199 miliar batang rokok atau urutan ke-4 setelah RRC (1.679 miliar batang). Amerika Serikat (480 miliar), Jepang (230 miliar) dan Rusia (230 miliar) (DepKes RI, 2005 ).

Sudah beberapa dasawarsa diketahui bahwa merokok menyebabkan konsekuensi serius. Merokok merupakan salah satu faktor paling beresiko yang paling bahaya, yang bisa menimbulkan masalah pada jantung, paru-paru dan peredaran darah (Christian). Kebiasaan merokok dapat menimbulkan gangguan paru berupa bronchitis dan emfisema. Pada kedua keadaan ini terjadi penurunan fungsi paru dibandingkan dengan yang tidak menderita penyakit tersebut. Selain itu pecandu rokok sering menderita penyakit batuk kronis, kepala pusing, perut mual, sukar tidur dan lain-lain. Kalau gejala-gejala diatas tidak segera diatasi maka gejala yang lebih buruk lagi akan terjadi, seperti semakin sulit untuk bernapas, kecepatan pernapasan bertambah, kapasitas vital berkurang, dan lain-lain (Usin, 1999).

Pernapasan adalah proses pergantian udara yang dibutuhkan oleh manusia untuk proses pembakaran dengan oksigen (O2) yang dikandung dalam udara ditampung dalam paru. Namun daya tampung paru setiap manusia berbeda-beda. Ada sebagian orang yang hanya menampung sedikit sekali oksigen dalam parunya, sehingga tidak cukup mampu untuk menyuplai oksigen dalam peredaran darah, ini akan menyebabkan tingkat kesehatan menurun. Di lain hal manusia memiliki daya kekuatan atau kesehatan yang berbeda-beda, ada yang daya tahan tubuhnya kuat dan ada manusia yang daya tahan tubuhnya lemah, ini tergantung pada kekebalan tubuhnya. Selain itu, gangguan pada sistem pernafasan dapat menurunkan kemampuan fungsi paru, dimana gangguan terhadap penurunan fungsi paru ini dapat diketahui dari volume paru atau kapasitas paru yang merupakan indikator untuk mengetahui kondisi faal paru apakah masih dalam kondisi yang prima ataukah tidak.
Kapasitas vital paru merupakan salah satu pengukuran volume paru yang menghitung jumlah udara maksimal ekspirasi setelah dilakukan inspirasi maksimal, dimana besarnya kapasitas vital paru sangat tergantung pada kemampuan paru dalam mengembang. Kemampuan paru dalam mengembang yang berarti kemampuan seseorang dalam menggunakan otot-otot pernafasan untuk mengembangkan rongga dada tergantung dari aktifitas dan latihan yang dilakukan seseorang.

Seiring pertambahan umur, kapasitas paru manusia akan menurun. Disamping itu jenis kelamin juga menentukan kapasitas paru seseorang. Laki-laki dewasa memiliki kapasitas paru yang lebih besar dari wanita dewasa (Aditama, 2005). Menurut Harrington (2005) fungsi paru yang ditampilkan dalam kapasits vital paru dan daya fisik berubah-ubah akibat sejumlah faktor non pekerjaan, yaitu beberapa faktor selain faktor lama bekerja diantaranya: Usia, jenis kelamin, ukuran paru, kelompok etnik, tinggi badan, kebiasaan merokok, toleransi latihan, kekeliruan pengamat, kekeliruan alat, dan suhu lingkungan sekitar.

Survey secara nasional menunjukkan bahwa pria yang tidak tamat sekolah atau tidak tamat SD merupakan perokok terbanyak. Makin tinggi tingkat pendidikan seseorang makin sedikit yang jadi perokok (Jamal, 2006).

Buruh bongkar muat pelabuhan adalah salah satu pekerjaan yang membutuhkan kapasitas paru yang maksimal agar dapat menghasilkan tenaga yang maksimal untuk bekerja. Selain itu semakin meningkatnya tuntutan hidup pada pekerja buruh menyebabkan peningkatan angka kecemasan dimana sebagian besar kecemasan itu diatasi dengan melakukan kebiasaan menghisap rokok.

Survey awal di pelabuhan Pulai Baai Propinsi Bengkulu ditemukan data dari 10 orang buruh, 5 orang merokok 20 batang perhari 3 orang $12-15$ batang perhari dan selebihnya kadang merokok kadang tidak. Selain itu dari Beberapa orang perokok tersebut mengatakan bahwa nafas mereka 
cenderung lebih pendek dibandingkan teman-teman mereka yang seusia tapi tidak atau jarang merokok. Tujuan penelitian ini diketahuinya hubungan merokok dengan kapasitas vital paru pada buruh pelabuhan Pulau Baai Bengkulu tahun 2009.

\section{BAHAN DAN CARA KERJA}

Desain penelitian ini adalah cross sectional. Sampel adalah sebagian dari buruh pelabuhan Pulau Baai Bengkulu tahun 2009, yang mempunyai kebiasaan merokok. Besar sampel ditentukan dengan menggunakan rumus besar, maka didapat 50 orang sebagai sampel penelitian. Teknik pe-ngambilan secara sistem random sampling (acak sederhana). Penelitian dilaksanakan di pelabuhan Pulau Baai Bengkulu. Pengumpulan data penelitian dilaksanakan sekitar satu bulan, yakni dari tanggal 17 Oktober - 15 November 2009.
Pengukuran dilaksanakan setiap hari Sabtu dan Minggu.

Pengumpulan data penelitian ini menggunakan data primer (data yang didapat langsung dari responden). Analisis yang digunakan adalah analisis univariat, bivariat dan multivariat menggunakan $\mathrm{Lo}$ gistic Regression Ganda.

\section{HASIL}

\section{Analisis Univariat}

Hasil analisis univariat dapat dilihat pada tabel dibawah ini yang menunjukkan bahwa hampir setengah responden $(46 \%)$ mempunyai kebiasaan merokok berat, sebagian besar $(74 \%)$ berada dalam status gizi normal, hampir setengahnya (44\%) mempunyai riwayat penyakit paru, lebih dari setengah-nya (52\%) berada dalam rentang usia $\geq 33$ tahun dan hampir setengahnya (40\%) mempunyai kapasitas vital paru yang tidak normal.

Tabel 1 Distribusi Frekuensi Responden Berdasarkan Kebiasaan Merokok, Riwayat Penyakit Paru, Status Gizi, Usia dan Kapasitas Vital Paru pada Buruh Pelabuhan Pulau Baai Bengkulu Tahun 2009

\begin{tabular}{|c|c|c|}
\hline Variabel & $\begin{array}{l}\text { Frekuensi } \\
\quad(\mathrm{n}=50)\end{array}$ & $\begin{array}{c}\text { Persentase } \\
(\%)\end{array}$ \\
\hline \multicolumn{3}{|l|}{ Kebiasaan merokok } \\
\hline 1. Merokok berat & 23 & 46 \\
\hline 2. Merokok sedang & 15 & 30 \\
\hline 3. Merokok ringan & 12 & 24 \\
\hline \multicolumn{3}{|l|}{ Status Gizi } \\
\hline 1. Kurus & 8 & 16 \\
\hline 2. Gemuk & 5 & 10 \\
\hline 3. Normal & 37 & 74 \\
\hline \multicolumn{3}{|l|}{ Riwayat penyakit paru } \\
\hline 1. Ada & 22 & 44 \\
\hline 2. Tidak ada & 28 & 56 \\
\hline \multicolumn{3}{|l|}{ Usia } \\
\hline 1. $\geq$ median & 26 & 52 \\
\hline 2. $<$ median & 24 & 48 \\
\hline \multicolumn{3}{|l|}{ Kapasitas vital paru } \\
\hline 1. Normal & 20 & 40 \\
\hline 2. Tidak normal & 30 & 60 \\
\hline
\end{tabular}

\section{Analisis Bivariat}

Analisis bivarat menggunakan uji Chi-Square $\left(\chi^{2}\right)$, dengan derajat kemakna- an sebesar $5 \%(\alpha=0,05)$. Hasil analisis bivariat dapat dilihat pada tabel 2 dibawah ini. 
Tabel 2. Hasil Analisis Bivariat Antara Kebiasaan Merokok, Riwayat Penyakit Paru, Status Gizi dan Usia dengan Kapasitas Vital Paru pada Buruh Pelabuhan Pulau Baai Bengkulu Tahun 2009

\begin{tabular}{|c|c|c|c|c|c|c|c|c|c|}
\hline \multirow[t]{2}{*}{ Variabel } & \multicolumn{2}{|c|}{$\begin{array}{c}\text { Kapasitas } \\
\text { Vital Paru } \\
\text { Normal } \\
\end{array}$} & \multicolumn{2}{|c|}{$\begin{array}{c}\text { Kapasitas Vital } \\
\text { Paru Tidak } \\
\text { Normal }\end{array}$} & \multirow{2}{*}{$\begin{array}{c}\text { Jumlah } \\
\mathrm{f} \\
\end{array}$} & \multirow[t]{2}{*}{$\%$} & \multirow[t]{2}{*}{ Nilai p } & \multirow[t]{2}{*}{ PR } & \multirow[t]{2}{*}{$951 \% \mathrm{CI}$} \\
\hline & $\mathrm{f}$ & $\%$ & $\mathrm{f}$ & $\%$ & & & & & \\
\hline Kebiasaan merokok & & & & & & & & & \\
\hline 1. Merokok berat & 5 & 21,7 & 18 & 78,3 & 23 & 100 & 0,00 & 10,8 & $2,095-55,67$ \\
\hline 2. Merokok sedang & 6 & 40 & 9 & 60 & 15 & 100 & 0,08 & 4,5 & $0,85-23,8$ \\
\hline 1. Kurus dan Gemuk & 5 & 38,5 & 8 & 615 & 13 & 100 & 1,00 & 0,917 & $0,251-3,350$ \\
\hline 2. Normal & 15 & 40,5 & 22 & 59,5 & 37 & 100 & & & \\
\hline Riwayat penyakit paru & & & & & & & & & \\
\hline 1. Ada & 4 & 20,0 & 16 & 80,0 & 20 & 100 & 0,039 & 0,219 & $0,059-0,810$ \\
\hline 2. < median & 12 & 50 & 12 & 50 & 24 & 48 & & & \\
\hline
\end{tabular}

Hubungan Kebiasaan Merokok dengan Kapasitas Vital Paru.

Hasil analisis bivariat menunjukkan bahwa dari 50 orang responden, sebagian besar $(78,3 \%)$ dari yang mempunyai kebiasaan merokok berat mempunyai kapasitas vital paru tidak normal. Hasil analisis didapatkan: 1) kebiasaan merokok berat mempunyai resiko sebesar 10,8 kali (95\%CI: 2,095-55,667) untuk mempunyai kapasitas vital paru tidak normal dibandingkan kebiasaan merokok ringan (nilai-p $=0,00$ ) pada buruh pelabuhan Pulau Baai Bengkulu tahun 2009.

\section{Hubungan Status Gizi dengan Kapasitas Vi- tal Paru.}

Hasil analisis bivariat menunjukkan bahwa dari 50 orang responden, lebih dari setengah $(61,5 \%)$ yang mempunyai status gizi kurus dan gemuk mempunyai kapasitas vital paru tidak normal. Hasil didapatkan nilai-p $=1,00, P R=0,917$ dan $95 \% \mathrm{CI}$ $=0,251-3,350$.

\section{Hubungan Riwayat Penyakit Paru dengan Kapasitas Vital Paru.}

Hasil analisis bivariat menunjukkan bahwa dari 50 orang responden sebagian besar $(80,0 \%)$ yang ada riwayat penyakit paru mempunyai kapasitas vital paru tidak normal. Hasil analisis didapatkan nilai- $\mathrm{p}=$ 0,039 , ada hubungan riwayat penyakit paru dengan kapasitas vital paru pada buruh pelabuhan Pulau Baai Bengkulu tahun 2009. $\mathrm{PR}=0,219$ dan $95 \% \mathrm{CI}=0,059-$ 0,810 , artinya orang yang ada riwayat penyakit paru tercegah sebesar 0,167 kali untuk mempunyai kapasitas vital paru tidak normal dibandingkan orang yang tidak ada riwayat penyakit paru pada buruh pelabuhan Pulau Baai Bengkulu tahun 2009.

\section{Hubungan Usia dengan Kapasitas Vital Pa- ru.}

Hasil analisis bivariat menunjukkan bahwa sebagian besar $(69,2 \%)$ yang berusia $\geq 33$ tahun mempunyai kapasitas vital paru tidak normal. Hasil analisis didapatkan nilai-p $=0,272$, tidak ada hubungan usia dengan kapasitas vital paru pada buruh pelabuhan Pulau Baai Bengkulu tahun 2009.

\section{Analisis Multivariat}

Analsis multivariat bertujuan untuk mengetahui variabel independen (kebiasaan merokok, riwayat penyakit paru, status gizi dan usia) yang dominan berhubungan dengan varaieel dependen (kapasitas vital 
paru). Untuk menyusun model dasar dari analisis multivariat, terlebih dahulu dilakukan analisis regresi logistik sederhana dengan ketentuan variabel yang berhak menjadi variabel kandidat adalah dengan hasil analisis bivariat diperoleh nilai-p $<0,25$.

Adapun variabel yang dapat masuk dalam analisis multivariat adalah: kebiasa- an merokok (nilai $\mathrm{p}=0,00$ ) dan riwayat penyakit paru (nilai-p $=0,012$ ). Kemudian dilakukan penyusunan model dasar dengan menganalisis hubungan kebiasaan merokok dan riwayat penyakit paru dengan kapasitas vital paru secara bersamaan. Hasil analisis multivariat pada tabel 3 .

Tabel 3 Hasil Analisis Multivariat Model Dasar Hubungan antara Kebiasaan Merokok dengan Kapasitas Vital Paru pada Buruh Pelabuhan Pulau Baai Bengkulu Tahun 2009

\begin{tabular}{lccc}
\hline \multicolumn{1}{c}{ Variabel } & Nilai p & PR & $95 \%$ CI \\
\hline Kebiasaan Merokok & & & $1,67-50,65$ \\
- Merokok berat & 0,11 & 9,20 & $0,80-26,22$ \\
- Merokok sedang & 0,87 & 4,59 & - \\
- Merokok ringan & - & - & $0,06-1,07$ \\
Riwayat penyakit paru & 0,06 & 0,26 & \\
\hline
\end{tabular}

-2LL: 53,995

G: 13,306

Berdasarkan tabel 3, diketahui bahwa Kebiasaan merokok_mempunyai nilai $\mathrm{p}=$ $0,11, \mathrm{PR}=9,20,95 \% \mathrm{CI}=1,67-50,65$, artinya orang yang merokok berat mempunyai risiko sebesar 9,20 kali untuk menda- patkan nilai kapasitas vital paru yang tidak normal. Selanjutnya dilakukan analisis interaksi. Hasil analasis interaksi dapat dilihat pada tabel 4 .

Tabel 4 Hasil Analisis Interaksi dalam Hubungan Merokok dengan Kapasitas Paru pada Buruh Pelabuhan Pulau Baai Kota Bengkulu Tahun 2009

\begin{tabular}{lccc}
\hline \multicolumn{1}{c}{ Variabel } & $\begin{array}{c}\text { Nilai-p } \\
\text { Crude }\end{array}$ & Nilai-p Adjust-1 & Kesimpulan \\
\hline Merokok & 0,136 & 0,038 & - \\
Riwayat penyakit paru & 0,055 & 0,062 & - \\
Merokok_Riwayat penyakit paru & 0,012 & - & Bukan variabel interaksi \\
\hline
\end{tabular}

Tabel diatas menunjukkan bahwa setelah dimasukkan variabel interaksi antara merokok dengan riwayat penyakit paru (merokok_riwayat penyakit paru), maka didapatkan nilai- $p=0,136$, artinya variabel merokok_riwayat penyakit paru bukan variabel interaksi. Selanjutnya dilakukan analisis confounding. Hasil analasis confounding dapat dilihat pada tabel 5.

Tabel 5 Hasil Analisis Confounding dalam Hubungan Merokok dengan Kapasitas Paru Pada Buruh Pelabuhan Pulau Baai Kota Bengkulu Tahun 2009

\begin{tabular}{lccc}
\hline \multicolumn{1}{c}{ Variabel } & PR & PR & Kesimpulan \\
& Crude & Adjust & \\
\hline Merokok & 9,202 & 10,8 & - \\
Riwayat penyakit paru & 0,258 & 4,5 & Variabel confounding (16,48\%) \\
\hline
\end{tabular}

Tabel diatas menunjukkan bahwa setelah dilakukan analisis confounding, maka hasil perhitungan didapatkan $16,48 \%$, artinya variabel riwayat penyakit paru meru- pakan variabel confounding. Berdasarkan hasil analsis diatas, maka disusun model akhir dari analisis multivariat, seperti pada tabel 6. 
Tabel 6 Hasil Analisis Multivariat Model Akhir pada Hubungan antara Kebiasaan Merokok dengan Kapasitas Vital Paru Pada Buruh Pelabuhan Pulau Baai Bengkulu Tahun 2009

\begin{tabular}{lccc}
\hline \multicolumn{1}{c}{ Variabel } & Nilai p & PR & 95\%CI \\
\hline Kebiasaan Merokok & & & $1,67-50,65$ \\
- Merokok berat & 0,11 & 9,20 & $0,80-26,22$ \\
- Merokok sedang & 0,87 & 4,59 & - \\
- Merokok ringan & - & - & $0,06-1,07$ \\
Riwayat penyakit paru & 0,06 & 0,26 &
\end{tabular}

Berdasarkan tabel diatas, diketahui bahwa kebiasaan merokok_mempunyai nilai $\mathrm{p}=0,11, \mathrm{PR}=9,20,95 \% \mathrm{CI}=1,67$ 50,65 , artinya orang yang merokok berat mempunyai risiko sebesar 9,20 kali untuk mendapatkan nilai kapasitas vital paru yang tidak normal, setelah dikontrol riwayat penyakit paru.

\section{PEMBAHASAN}

Hubungan Kebiasaan Merokok dengan Kapasitas Vital Paru pada Buruh Pelabuhan Pulau Baai Bengkulu tahun 2009.

Hasil analisis dengan uji chi square diketahui bahwa ada hubungan merokok dengan kapasitas vital paru pada buruh pulau Baai Bengkulu tahun 2009. Orang yang merokok berat mempunyai resiko se-besar 10,8 kali (95\%CI: 2,095-55,667) untuk mempunyai kapasitas vital paru tidak normal dibandingkan kebiasaan merokok ringan (nilai-p $=0,00$ ) pada buruh pelabuhan Pulau Baai Bengkulu tahun 2009. Sedangkan untuk kebiasaan merokok sedang dan ringan tidak ada hubungannya dengan kapasitas vital paru pada buruh pelabuhan Pulau Baai Bengkulu tahun 2009.

Hasil penelitian ini sesuai dengan pendapat yang dikemukakan oleh Joko Suyono (2001), bahwa inhalasi asap tembakau baik primer maupun sekunder dapat menyebabkan penyakit saluran pernafasan pada orang dewasa. Asap rokok mengiritasi paru-paru dan masuk ke dalam aliran darah. Merokok lebih merendahkan kapasitas vital paru dibandingkan beberapa bahaya kesehatan akibat kerja.
Kebiasaan merokok dapat menimbulkan gangguan paru berupa bronchitis dan emfisema. Pada kedua keadaan ini terjadi penurunan fungsi paru dibandingkan dengan yang tidak menderita penyakit tersebut. Selain itu pecandu rokok sering menderita penyakit batuk kronis, kepala pusing, perut mual, sukar tidur dan lainlain. Kalau gejala diatas tidak segera diatasi maka gejala yang lebih buruk lagi akan terjadi, seperti semakin sulit untuk bernapas, kecepatan pernapasan bertambah, kapasitas vital berkurang, dan lainlain (Jos Usin, 1999).

Merokok dapat menyebabkan perubahan struktur dan fungsi saluran pernapasan dan jaringan paru. Pada saluran napas besar, sel mukosa membesar (hipertrofi) dan kelenjar mucus bertambah banyak. Pada saluran pernapasan kecil, terjadi radang ringan hingga penyempitan akibat bertambahnya sel dan penumpukan lendir. Pada jaringan paru terjadi peningkatan jumlah sel radang dan kerusakan alveoli. Akibat perubahan anatomi saluran napas, pada perokok akan timbul perubahan klinisnya. Hal ini menjadi dasar utama terjadinya penyakit obstruktif paru menahun (Depkes RI, 2003).

\section{Hubungan Status Gizi dengan Kapasitas Vi- tal Paru pada Buruh Pelabuhan Pulau Baai Bengkulu tahun 2009.}

Hasil analisis diketahui bahwa tidak ada hubungan antara status gizi dengan kapasitas vital paru pada buruh pelabuhan Pulau Baai Bengkulu tahun 2009.

Status Gizi seseorang dapat mempengaruhi kapasitas vital paru. Orang kurus 
panjang biasanya kapasitasnya lebih dari orang gemuk pendek. Masalah kekurangan dan kelebihan gizi pada orang dewasa (usia 18 tahun keatas) merupakan masalah penting, karena selain mempunyai resiko penyakit-penyakit tertentu, juga dapat mempengaruhi produktivitas kerja. Oleh karena itu, pemantauan keadaan tersebut perlu dilakukan secara berkesinambungan. Salah satu cara adalah dengan mempertahankan berat badan ideal atau normal.

\section{Hubungan Riwayat Penyakit Paru dengan Kapasitas Vital Paru pada Buruh Pelabu- han Pulau Baai Bengkulu tahun 2009.}

Hasil analisis didapatkan ada hubungan riwayat penyakit paru dengan kapasitas vital paru pada buruh pelabuhan Pulau Baai Bengkulu tahun 2009. Tetapi mempunyai resiko yang terbalik yaitu: orang yang ada riwayat penyakit paru terlindungi sebesar 0,219 kali mendapatkan kapasitas vital paru yang tidak normal

Kapasitas vital paru akan berkurang pada penyakit paru-paru, pada penyakit jantung (yang menimbulkan kongesti paruparu) dan kelemahan otot paru-paru (Guyton, 1997). Penyakit yang dapat mempengaruhi kapasitas paru, meliputi: Emfisema paru kronik, Pneumonia, Atelektasis, Asma dan Tuberkulosis.

Emfisema paru kronik merupakan kelainan paru dengan patofisiologi berupa infeksi kronik, kelebihan mucus, dan edema pada epitel bronchiolis yang mengakibatkan terjadinya obstriktif dan destruktif paru yang kompleks sebagi akibat mengkonsumsi rokok.

Pneumonia mengakibatkan dua kelainan utama paru yaitu penurunan luas permukaan membran pernafasan dan menurunnya resiko ventilasi perfusi. Kedua efek ini mengakibatkan menurunnya kapasitas paru. Atelektasis berarti alveoli paru mengempis atau kolaps. Akibatnya terjadi penyumbatan pada alveoli sehingga tahanan aliran darah meningkat dan terjadi penekanan dan pelipatan pembuluh darah sehingga volume paru berkurang.
Pada penderita asma akan terjadi penurunan kecepatan ekspirasi dan volume inspirasi. Pada penderita tuberkulosis stadium lanjut, banyak timbul daerah fibrosis di seluruh paru dan mengurangi jumlah paru fungsional, sehingga mengurangi kapasitas paru.

\section{Hubungan Usia dengan Kapasitas Vital Pa- ru pada Buruh Pelabuhan Pulau Baai Beng- kulu tahun 2009.}

Hasil analisis didapatkan tidak ada hubungan usia dengan kapasitas vital paru pada buruh pelabuhan Pulau Baai Bengkulu tahun 2009.

Dalam keadaan yang nor-mal kedua paru dapat menampung sebanyak \pm 5 liter. Waktu ekspirasi, di dalam paru masih tertinggal \pm 3 liter udara. Pada waktu bernafas biasa udara yang masuk ke dalam paru $2600 \mathrm{cc}$ (2,5 liter). Jumlah pernafasan dalam keadaan normal: Orang Dewasa : 16-18 kali per menit, Anak-anak : 24 kali per menit dan bayi kira-kira : 30 kali per menit.

Dari keterangan diatas menunjukkan bahwa pada orang dewasa jumlah pernafasannya antara 16-18 kali per menit, pada anak-anak sekitar 24 kali per menit sedangkan pada bayi kira-kira 30 kali per menit. Walaupun pada pernapasan pada orang dewasa lebih sedikit daripada anak-anak dan bayi, akan tetapi kapasitas vital paru orang dewasa lebih besar dibandingkan dengan anak-anak dan bayi. Dalam keadaan tertentu keadaan tersebut akan berubah misalnya akibat dari suatu penyakit, pernafasan bisa bertambah cepat dan sebaliknya (Syaifuddin, 1997).

Usia berhubungan dengan proses penuaan atau bertambahnya umur. Semakin tua usia seseorang maka semakin besar kemungkinan terjadi penurunan fungsi paru (Suyono, 2001). 
Hubungan Kebiasaan Merokok dengan Kapasitas Vital Paru Pada Buruh Pelabuhan Pulau Baai Bengkulu Tahun 2009, Setelah Dikontrol dengan Riwayat Penyakit Paru Sebelumnya.

Selama beberapa tahun terakhir, ilmuwan telah membuktikan bahwa zat-zat kimia yang terkandung dalam rokok dan asap rokok dapat mempengaruhi orang yang tidak merokok karena asap rokok mengandung zat yang bersifat racun.

Nikotin diterima reseptor asetilkotinnikotinik yang kemudian membagi ke jalur imbalan dan jalur adrenergenik. Pada jalur imbalan, perokok akan merasakan nikmat, memacu sistem dopaminergik. Hasilnya perokok akan merasa lebih tenang, daya pikir serasa lebih cemerlang, dan mampu menekan rasa lapar. Di jalur adrenergik, zat ini akan mengaktifkan sistem adrenergik pada bagian otak lokus seruleus yang mengeluarkan sorotin. Meningkatnya sorotin menimbulkan rangsangan rasa senang sekaligus keinginan mencari rokok lagi. Hal inilah yang menyebabkan perokok sangat sulit meninggalkan rokok, karena sudah ketergantungan pada nikotin. Ketika ia berhenti merokok rasa nikmat yang diperolehnya akan berkurang. (Mu'tadin, 2002)

\section{KESIMPULAN}

1. Kapasitas vital paru tidak berhubungan dengan status gizi dan usia.

\section{DAFTAR KEPUSTAKAAN}

Departemen Kesehatan Republik Indonesia, 1999. Modul 10 Bayi Baru Lahir, Jakarta

H. Beers, Mark dan Robert Berko,. 2007. Neonatal Problems : Sepsis Neonatorum. Diakses dari http://www.merck.com/mmhe/index.html, Februari 2007

Klaus dan Fanaroff Care of the High Risk Neonate, 1998. Surjono, Achmad Penatalaksanaan Neonatus Resiko Tinggi Edisi 4. EGC. Jakarta.

Kompas, 5 April 2005.

L. Tobing, Bonar. 2003. Luaran Ibu dan Anak Pada Persalinan Terdaftar dan Tidan Terdaftar Di RSUD H. Adam Malik dan RS Dr. Pirngadi Medan. Diakses dari http://www.google.com, Maret 2007.
2. Kapasitas vital paru berhubungan dengan kebiasaan merokok dan riwayat penyakit paru.

3. Riwayat penyakit paru merupakan variabel confounding hubungan kebiasaan merokok dengan kapasitas vital paru pada buruh pelabuhan Pulau Baai Bengkulu tahun 2009.

Saran Bagi Buruh Pelabuhan Pulau Baai, diharapkan dengan adanya hasil penelitian ini dapat memotivasi para buruh untuk mengurangi konsumsi rokok dikarenakan akibat yang ditimbulkan pada paruparunya. Mencoba mengganti konsumsi rokok dengan mengunyah permen yang beraroma cengkeh. Bagi Civitas Akademika, diharapkan dengan adanya hasil penelitian ini diharapakan dapat menyumbangkan suatu fenomena di komunitas buruh pelabuhan sehingga dapat melanjutkan penelitian ini dengan penelitian yang lebih baik, antara lain: melibatkan lebih banyak responden, dengan variabel yang lebih banyak dan dengan desain kohor. Bagi Tenaga Kesehatan seperti Perawat, hendaknya lebih menggiatkan usaha promotif dan preventif berhenti merokok pada masyarakat, terutama pada kelompok usia produktif dengan menjelaskan dampak-dampak yang bisa ditimbulkan oleh rokok, baik bagi si perokok sendiri maupun bagi orang lain di sekitarnya.

Mansjoer, Arif, 2000. Kapita Selekta Kedokteran EdisiKe tiga Jilid 2. Media Aesculaprus FKUI. Jakarta.

Manuaba, I.B.G, 1998. Ilmu Kebidanan, Penyakit Kandungan dan Keluarga Berencana. EGC. Jakarta.

Marjono, Antonius Budi, 1999. Pengantar Perinatalogi. Diakses dari http://www.google.com, Februari 2007

Markum, A.H, 1999. Buku Ajar IlmuKesehatan Anak Jilid I. Bagian Ilmu Kesehatan Anak FKUI. Jakarta.

Nelson, 1999. Ilmu Kesehatan Anak I. EGC. Jakarta.

Notoatmodjo, Soekidjo, 2005. Metodelogi Penelitian Kesehatan. Rineka Cipta. Jakarta. 
P Lubis, Cahiruddin, 2003. Infeksi Nosokomial Pada Neonatus. Diakses dari http://www.google.com, Februari 2007.

Rendle, John, A.P. Gray dan J. A. Dodge, 2001. Ikhtisar Penyakit Anak . Edisi 9 . Binarupa Aksara. Jakarta.

Sitohang, Nur Asnah, 2004. Asuhan Keperawatan Pada Bayi Berat Lahir Rendah. Diakses dari http://www.google.com, Februari 2007.
Suara Pembaharuan, Jum'at 23 Agustus 2003.

Tanaya, 2007. Sepsis Neonatorum. Diakses dari http://www.google.com, Februari 2007.

The Clinical Use of Drugs, 1997. Neonatal Infections. Diakses dari http://www.google.com, Februari 2007. 